\title{
TREATMENT OF THE POPLITEAL CYST IN THE RHEUMATOID KNEE
}

\author{
I. M. Pinder, Bath, SOMERSET
}

From the Bath and Wessex Orthopaedic Hospital, Bath

A recent report on the surgical treatment of a popliteal cyst in a patient with rheumatoid arthritis suggested that excision of the cyst should be followed after some weeks by anterior synovectomy of the knee (Newton 1971). The good results of anterior synovectomy as a logical primary treatment are presented in this paper.

TABLE I

Details of The Cysts

\begin{tabular}{|c|c|c|c|c|c|c|c|}
\hline \multirow{2}{*}{$\begin{array}{l}\text { Case } \\
\text { number }\end{array}$} & \multirow{2}{*}{$\underset{(\text { years })}{\text { Age }}$} & \multirow[b]{2}{*}{ Sex } & \multirow{2}{*}{$\begin{array}{c}\text { Duration } \\
\text { of } \\
\text { disease } \\
\text { (years) }\end{array}$} & \multirow{2}{*}{$\begin{array}{c}\text { Duration of cyst before operation } \\
\text { (months) }\end{array}$} & \multicolumn{2}{|c|}{ Follow-up } & \multirow{2}{*}{$\begin{array}{l}\text { Arthrography } \\
\text { performed } \\
\text { after } \\
\text { operation }\end{array}$} \\
\hline & & & & & $\begin{array}{c}\text { Time } \\
\text { (months) }\end{array}$ & $\begin{array}{c}\text { Cyst } \\
\text { palpable }\end{array}$ & \\
\hline 1 & 57 & Male & 22 & $\begin{array}{c}60 \text { (calf cyst present } 18 \text { months } \\
\text { before operation) }\end{array}$ & 20 & No & Yes \\
\hline 2 & 45 & Female & 8 & 24 & 18 & No & Yes \\
\hline 3 & 65 & Male & 8 & $\begin{array}{l}\text { Excision calf cyst } 19 \text { months ago, } \\
\text { recurred after } 8 \text { months }\end{array}$ & 4 & No & No \\
\hline 4 & 67 & Female & 4 & 6 (calf cyst and popliteal cyst) & 13 & No & Yes \\
\hline 5 & 76 & Female & 4 & 24 & 6 & No & No \\
\hline 6 & 56 & Female & $3 \frac{1}{2}$ & $\begin{array}{c}6 \text { (popliteal and calf cyst with } \\
\text { cross fluctuations) }\end{array}$ & 11 & No & Yes \\
\hline 7 & 49 & Female & 9 & 60 & 9 & No & Yes \\
\hline 8 & 76 & Female & 10 & $\begin{array}{c}\text { Right } 20 \\
\text { Left } 20 \text { (cyst excised and } \\
\text { recurred in under one year) }\end{array}$ & $\begin{array}{r}50 \\
7\end{array}$ & $\begin{array}{l}\text { No } \\
\text { No }\end{array}$ & $\begin{array}{l}\text { Yes } \\
\text { Yes }\end{array}$ \\
\hline 9 & 65 & Male & 5 & 12 & 6 & No & Yes \\
\hline 10 & 44 & Male & 3 & 18 & 6 & No & Yes \\
\hline 11 & 51 & Male & 1 & 1 & 5 & No & No \\
\hline 12 & 62 & Male & 9 & 12 & 5 & No & Yes \\
\hline 13 & 59 & Male & 16 & $\begin{array}{c}\text { Left } 4 \\
\text { Right } 4 \text { (popliteal and calf cyst) }\end{array}$ & $\begin{array}{l}3 \\
3\end{array}$ & $\begin{array}{l}\text { No } \\
\text { Calf cyst } \\
\text { palpable }\end{array}$ & $\begin{array}{l}\text { No } \\
\text { No }\end{array}$ \\
\hline 14 & 56 & Female & 3 & 3 & 3 & $\begin{array}{l}\text { Yes } \\
\text { (soft and } \\
\text { small) }\end{array}$ & No \\
\hline
\end{tabular}

\section{THEORY}

It is axiomatic that active rheumatoid disease may produce a large effusion into the knee, and it has been shown that quadriceps contraction causes a large rise in intracapsular pressure (Jayson and Dixon 1970a). The weakest point of the capsule yields to the rise in pressure: protrusion occurs into the popliteal fossa and may track into the calf. Elimination of the cause of fluid production should, therefore, result in the disappearance of the cyst. 


\section{THE PATIENTS}

Details of fourteen patients with rheumatoid arthritis are presented in Table I. Operation-The operation was done through a lateral parapatellar incision, with medial mobilisation of the patella to give access to the anterior tibio-femoral compartment. The synovium was resected using cutting diathermy: the membrane removed included the suprapatellar pouch and the anterior lining of the cruciate ligaments in the intercondylar notch. Manual compression of the cyst on flexion of the knee emptied the fluid with fibrinous clots into the intercondylar notch (Fig. 1). No attempt was made to seal the communication

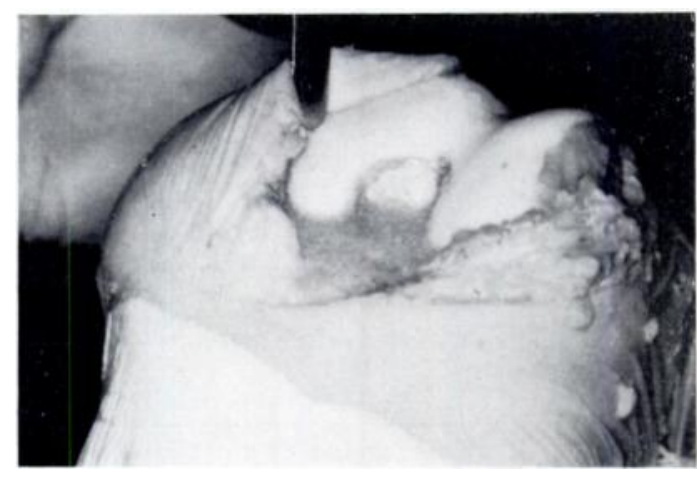

FiG. 1

Fluid containing fibrinous clots coming through the intercondylar notch at synovectomy as a result of pressure on the popliteal cyst.

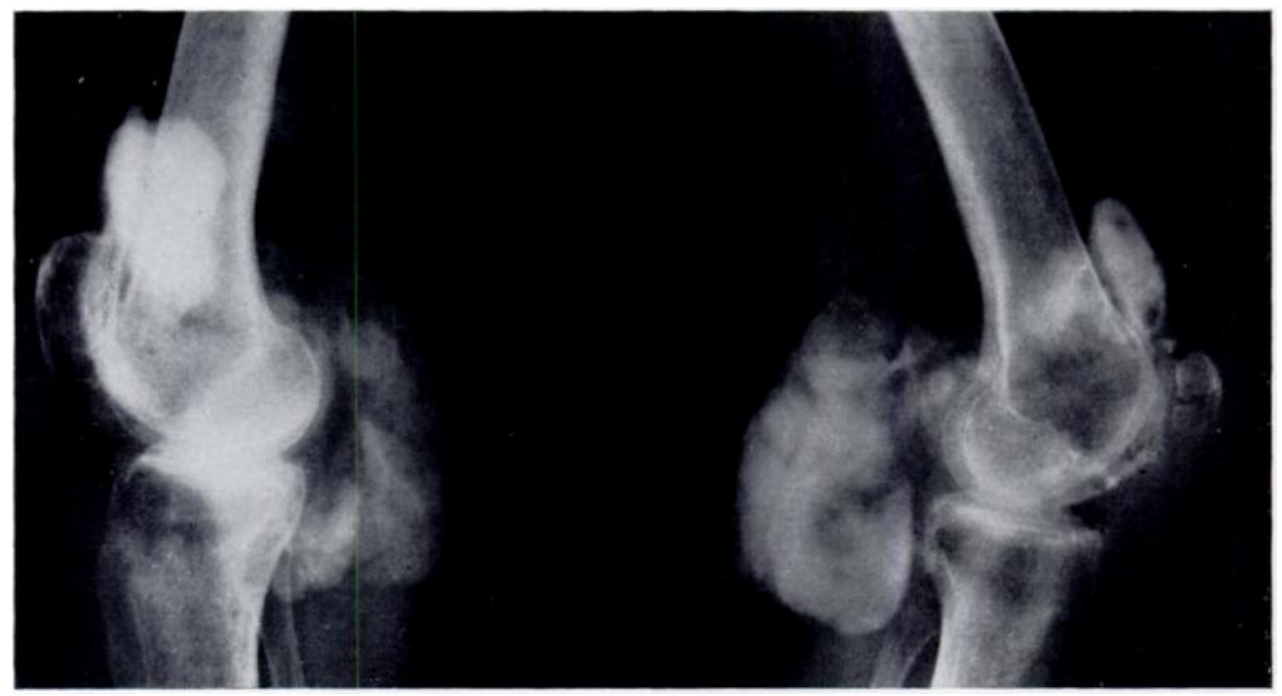

FIG. 2

Case 8-Bilateral arthrographs showing large popliteal cysts.

between the posterior capsule and the cyst. The wound was closed and wool and crepe bandages were applied from toes to the upper thigh. Suction drainage was not used.

The sutures were removed after two weeks, and if 90 degrees of flexion had not been regained within a further five days the knee was gently manipulated under general anaesthesia.

\section{ILLUSTRATIVE CASE REPORTS}

Case 8-A seventy-six-year-old woman, with sero-positive rheumatoid arthritis of ten years' duration presented in 1967 with a leaking popliteal cyst on the left side which had caused a 
discharging sinus in the popliteal space over a period of five months. Bilateral knee effusions with popliteal cysts had been present for twenty months (Fig. 2). The sinus and cyst were excised from the left knee and a month later anterior synovectomy was done on the right knee. One year later bilateral arthrographs confirmed that there was a recurrence of the left popliteal

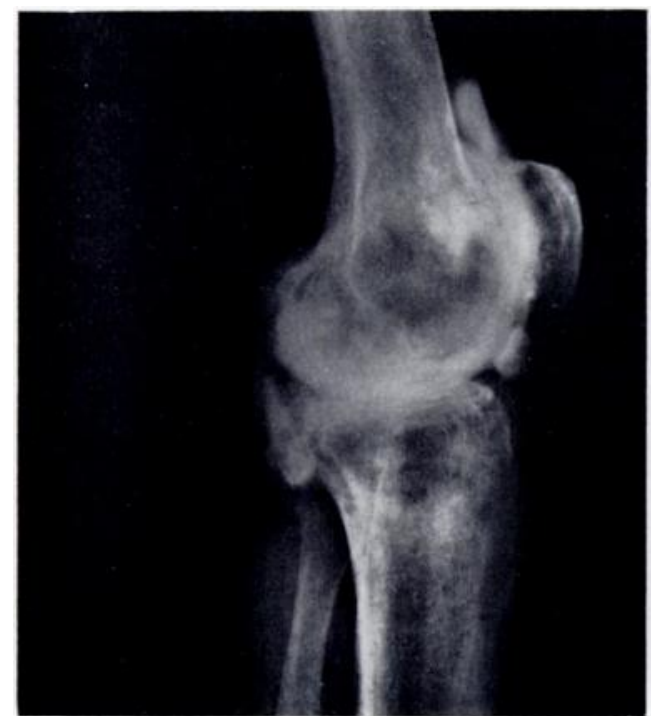

Fig. 3

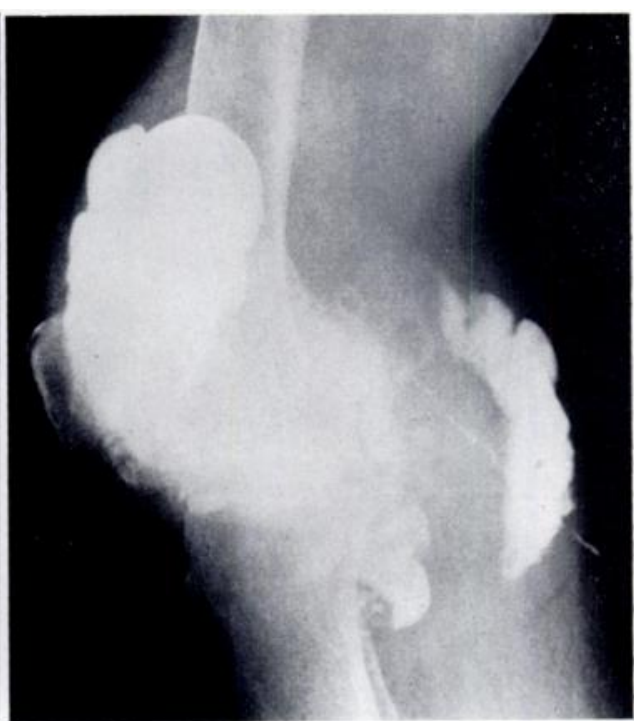

Fig. 4

Case 8. Figure 3-One year later, the right arthrograph shows no popliteal cyst after anterior synovectomy and a normal synovial outline. Figure 4-Four years after the original arthrographs, the left knee shows the continued presence of the popliteal cyst; the filling defect is caused by a large amount of fibrin in the cyst.
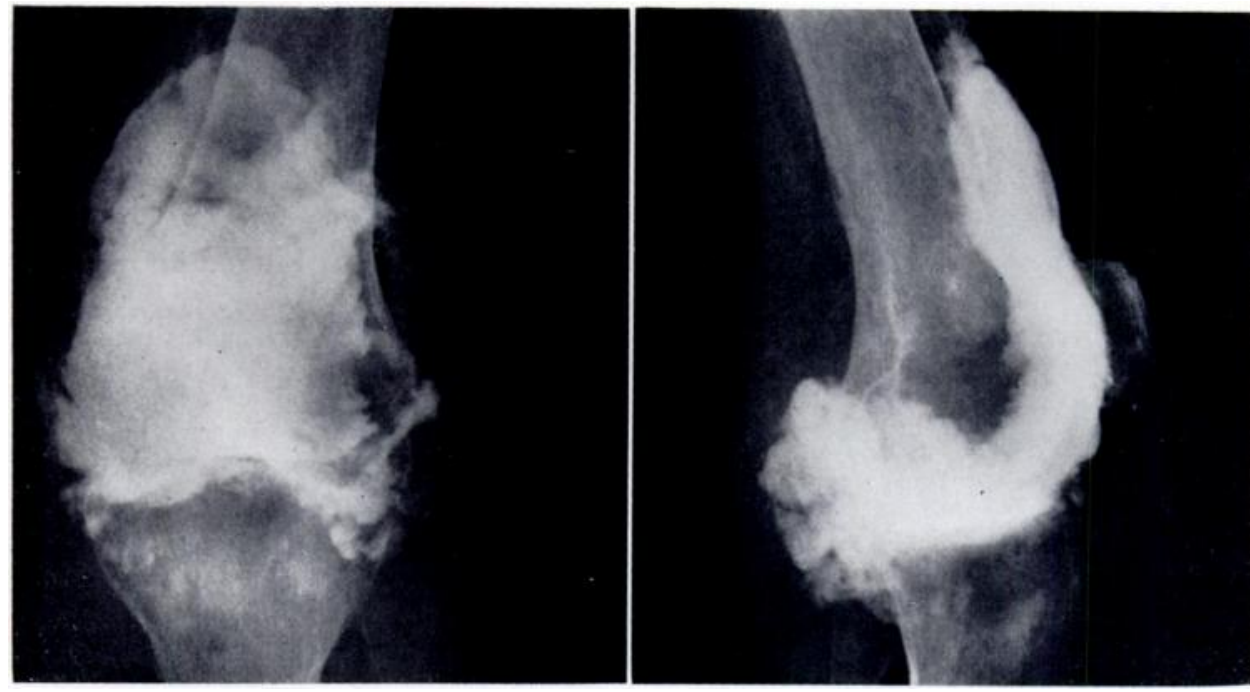

Fig. 5

Case 8-Arthrograph of the left kneeseven months after anterior synovectomy showing no popliteal cyst.

cyst with a large effusion into the knee but the right arthrograph revealed a normal outline (Fig. 3). She declined further operation until June 1971, when she was found to have a large effusion in the left knee in association with a large popliteal cyst (Fig. 4). Anterior synovectomy was done on the left knee, with a good result: the popliteal cyst was found not to be palpable on

VOL. 55 B, NO. 1, FEBRUARY 1973 
examination two weeks after this operation. At a recent review, seven months later, there was no effusion in either knee and no palpable popliteal cyst; arthrography confirmed these findings (Fig. 5).

Case 10-A forty-four-year-old man, a school teacher, with sero-positive rheumatoid arthritis of three years' duration complained of a painful swollen right knee associated with a popliteal cyst for eighteen months (Fig. 6). After synovectomy he made a rapid recovery with return

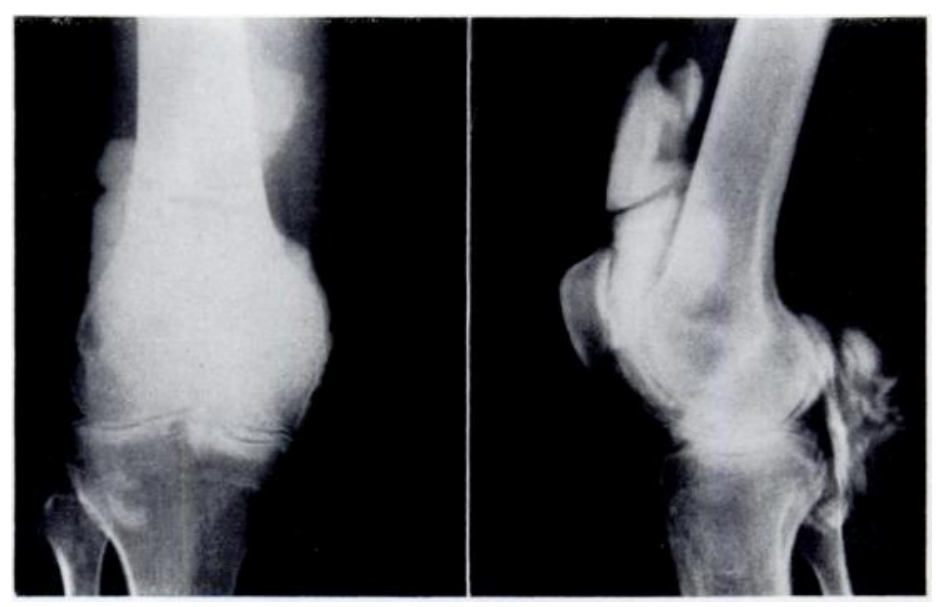

Fio. 6

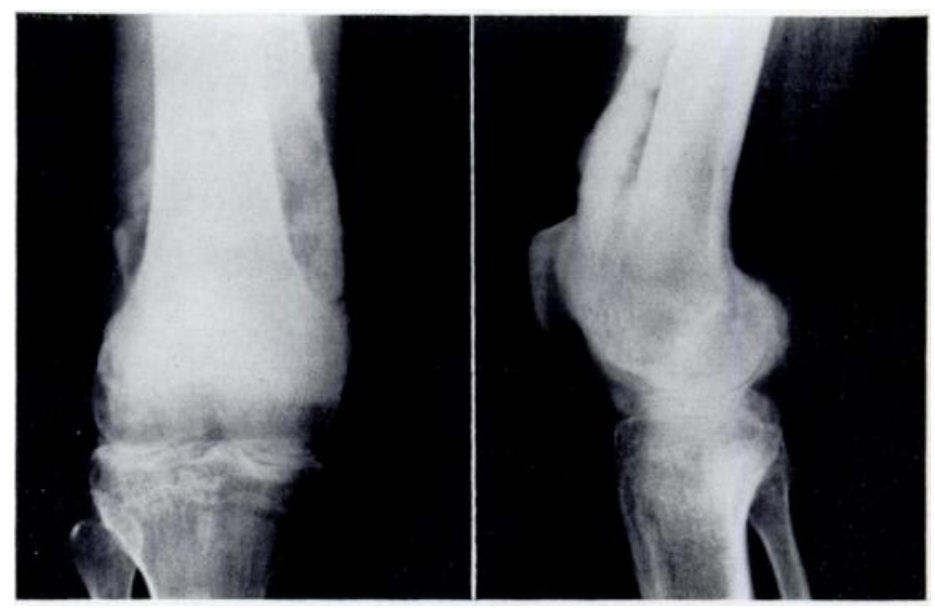

Fig. 7

Case 10. Figure 6-Arthrograph before operation on the right knee showing a popliteal cyst. Figure 7-The arthrograph two months after anterior synovectomy shows no cyst.

of full movement within three weeks, without manipulation. Examination two weeks after operation showed no evidence of a popliteal cyst; this observation was confirmed two months later by arthrography (Fig. 7).

Case 7-A forty-nine-year-old woman, with a nine years' history of rheumatoid arthritis presented with effusions in both knees and a popliteal cyst on the left side of five years' duration. After synovectomy she made an uneventful recovery and two weeks later no palpable popliteal cyst was found. At a recent review, nine months after operation, arthrography confirmed the absence of the popliteal cyst (Fig. 8). 
DISCUSSION

Wilson, Eyre-Brook and Francis (1938) postulated that a chronic knee effusion with raised intracapsular pressure would be necessary to produce a hernial protrusion into the

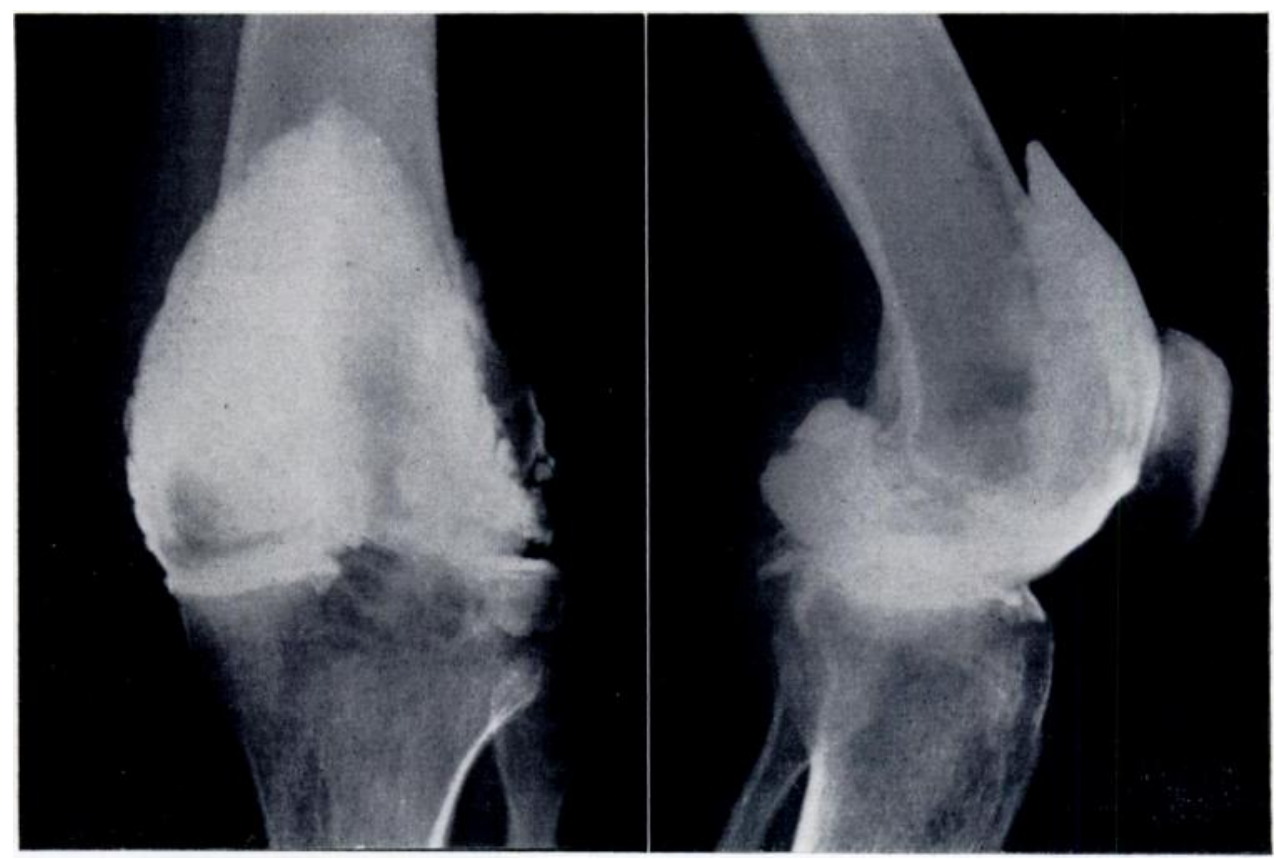

FIG. 8

Case 7-Nine months after anterior synovectomy there is no popliteal cyst.

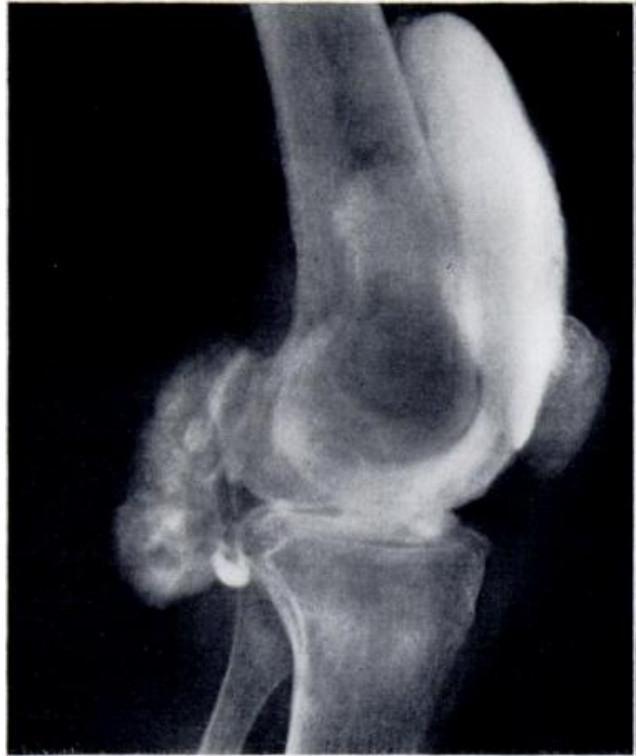

FiG. 9

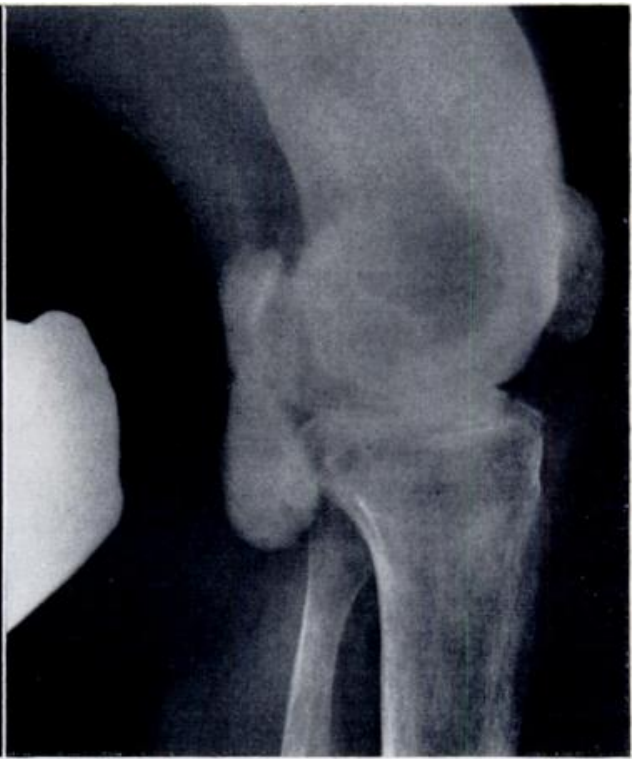

Fig. 10

Case 13-Arthrograph showing how pressure on the popliteal fossa causes a flow of fluid back into the knee joint.

popliteal fossa. They suggested that a flap valve mechanism was operative in one of their cases. Haggart (1938) said that of ten cysts operated upon by him, nine were true posterior 
herniae and one was an enlargement of the semimembranosus bursa. Jayson and Dixon $(1970 b)$ showed that there was a pressure gradient between the knee and the cyst.

In the present series of patients, emptying of the cyst contents (fluid and fibrin clots) into the knee through the intercondylar notch was a constant feature at operation; deliberate pressure on the cyst produced a further flow of cyst contents. These features are compatible if the circumstances at operation are taken into consideration. The fully flexed knee results in relaxation of the semimembranosus and gastrocnemius muscle bellies, causing a loss of the flap valve effect. In two cases it was possible by applying pressure to get a certain filling of the knee (Figs. 9 and 10), presumably due to valvular incompetence. Several patients had an extension of the popliteal cyst into the calf at some stage, and cross fluctuation could be

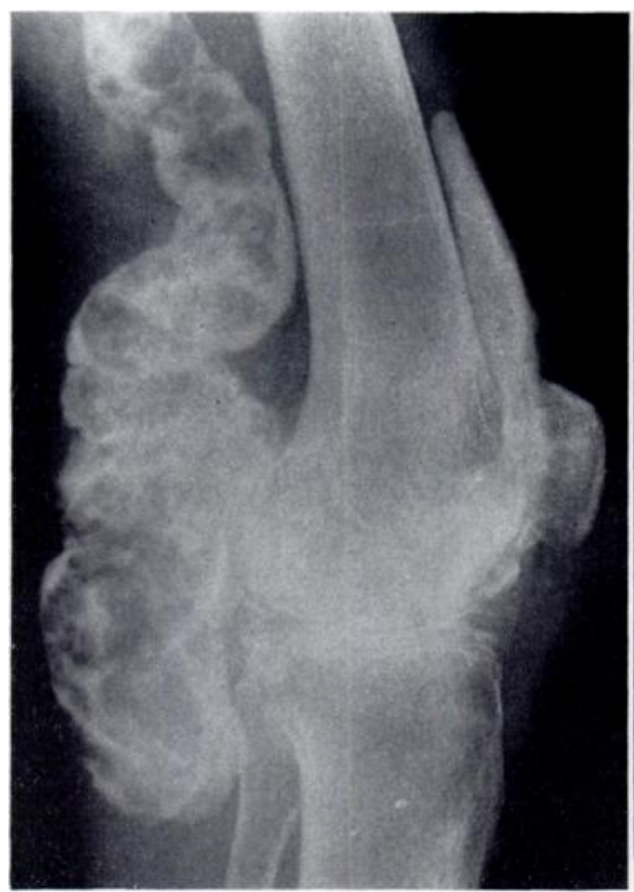

Fig. 11

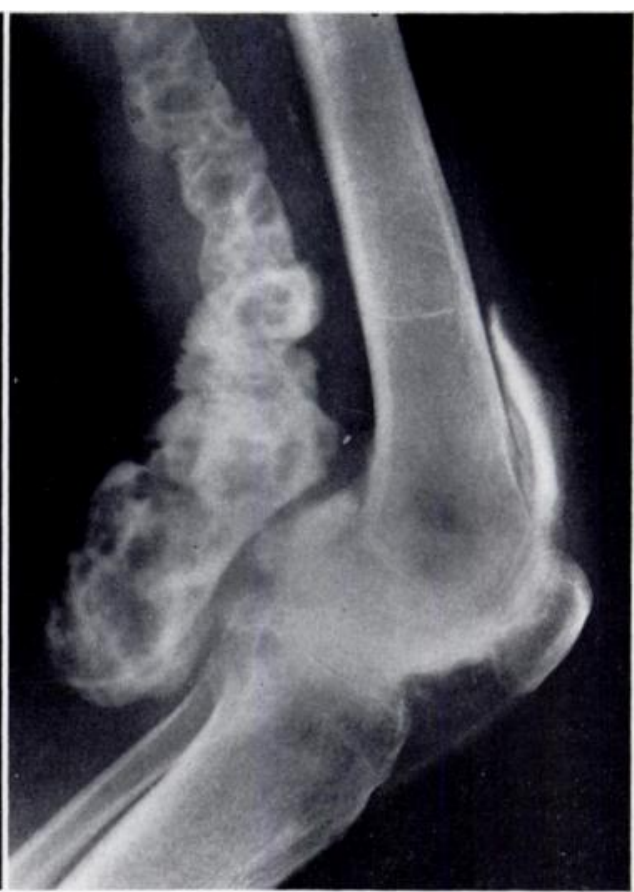

Fig. 12

Case 14-The arthrograph in Figure 11 shows the cyst extending proximally into the thigh. Figure 12Flexion has caused a rise in pressure in the knee and, transmitted to the cyst, has caused it to straighten out.

demonstrated between popliteal and calf cyst. In one case a serpiginous proximal extension of the cyst into the thigh was shown on arthrography (Fig. 11); flexion of the knee with the resulting rise in pressure transmitted to the cyst caused it to uncoil (Fig. 12). The direction taken by the contents of a ruptured popliteal cyst obviously depends on the weakest point of the cyst wall; it is usually downwards into the calf. Popliteal cysts are not common, and it is suggested that there are two modes of production: firstly, the filling of a semimembranosus bursa which resists rupture into the calf; and secondly, hernial protrusion into the popliteal fossa which has a weaker wall and is thus more likely to give rise to further extensions.

After operation, the calf cyst appears to take a considerable time to disappear, although filling cannot be demonstrated on arthrography; this is presumably because of the amount of fibrin in the cyst cavity. A further flare-up of rheumatoid activity in the knee with the development of an effusion could result in the reappearance of a popliteal cyst. In this small series this has not occurred. The correct treatment if there was a recurrence of the popliteal 
cyst would be further anterior synovectomy. Excision of the calf cyst and popliteal cyst, although technically satisfying at the time, appears doomed to failure; the cysts recurred in less than a year after operation. Anterior synovectomy does result in the disappearance of the popliteal cyst.

\section{SUMMARY}

1. Anterior synovectomy was undertaken in sixteen knees of fourteen patients with rheumatoid arthritis associated with popliteal or calf cysts. Subsequent changes in the knees and cysts were observed clinically and by arthrography.

2. In all instances there was alleviation of symptoms and in fourteen cases the cysts disappeared.

3. It is suggested that anterior synovectomy is the logical treatment of a posterior cyst associated with rheumatoid arthritis of the knee.

I wish to thank Mr P. M. Yeoman for help and criticism in the preparation of this paper. Mr A. E. Burton, Mr P. M. Yeoman, Mr J. R. Kirkup and Mr P. Bliss kindly gave me access to their patients and records.

\section{REFERENCES}

Haggart, G. E. (1938): Posterior Hernia of the Knee Joint. Journal of Bone and Joint Surgery, 20, 363.

JAyson, M. I. V., Dixon, A. St J. (1970a): Intra-articular Pressure in Rheumatoid Arthritis of the Knee. III. Pressure Changes during Joint Use. Annals of the Rheumatic Diseases, 29, 401.

Jayson, M. I. V., Dixon, A. St J. (1970b): Valvular Mechanisms in Juxta-articular Cysts. Annals of the Rheumatic Diseases, 29, 415.

Newton, D. (1971): Investigations of Calf Swellings. Journal of Bone and Joint Surgery, 53-B, 770.

Wilson, P. D., Eyre-Brook, A. L., and Francis, J. D. (1938): A Clinical and Anatomical Study of the Semimembranosus Bursa in Relation to Popliteal Cyst. Journal of Bone and Joint Surgery, 20, 963. 